\title{
Synthesis and Adsorption Properties of 4 -Vinylpyridine, Styrene and Maleic Anhydride Copolymer in Situ Immobilized on Silica Surface
}

\author{
E. S. Yanovska ${ }^{a}$, L. O. Vretik ${ }^{a}$, O. Kondratenko ${ }^{c}$, O. A. Nikolaeva ${ }^{a}$, D. Sternik ${ }^{b}$, and \\ O. Yu. Kychkyruk
}

${ }^{a}$ Taras Shevchenko Kyiv National University, Kyiv, Ukraine; ${ }^{b}$ Maria Curie-Skłodowska University, Lublin, Poland; 'Ivan Franko Zhytomyr State University, Zhytomyr, Ukraine

\begin{abstract}
A new mineral-organic composite by in situ immobilization of poly(4-vinylpyridine-co-styrene-co-maleic anhydride) on the silica gel surface was synthesized. According to TG-analysis, the composite contained $31.84 \mathrm{wt} . \%$ of immobilized copolymer. The highest sorption activity of a new composite was established towards microquantities of $\mathrm{Cu}$ (II) ions in neutral medium as well as towards $\mathrm{Pb}$ (II) and $\mathrm{Fe}$ (III) ions in a slightly acidic medium with the background of phthalate buffer and no sorption activity towards $\mathrm{Cd}(\mathrm{II})$ ions. The composite obtained exhibits a sorption capacity higher in $1.88,5.00$ and 3.35 times for $\mathrm{Fe}(\mathrm{III}), \mathrm{Cu}(\mathrm{II})$ and $\mathrm{Pb}$ (II) ions respectively in comparison with parent silica gel.
\end{abstract}

\section{KEYWORDS}

Adsorption; poly(4vinylpyridine-co-styren-comaleic anhydride); in situ immobilization; silica gel surface; heavy metals

\section{Introduction}

Pyridine and its derivatives are well-known ligands that form strong complexes with the ions of the most transition metals $[1,2]$. Processes of complex formation are inherent to pyridine-containing polymers, too $[3,4]$. Therefore, the modification of the surface of porous inorganic materials with pyridine-containing polymers is a perspective approach for preparation of composite complex-forming sorbents towards metal cations due to their interaction with Nitrogen moiety of pyridine fragment of immobilized polymer.

One of the promising ways of organo-mineral composite materials preparation with interesting and valuable sorption properties is the in situ polymer immobilization on the surface of a porous inorganic carrier - a formation of an immobilized polymer layer in the presence of inorganic carrier particles [5-7] during polymer syntheses.

This method of attaching polymers onto an inorganic surface has several advantages over simple mixing of pre-synthesized polymer with inorganic carrier or chemical bonding of polymer with inorganic surface.

In the case of in situ copolymerization, it is possible to create a polymeric layer on the surface of an inorganic carrier with the most optimal ratio of copolymer components. 
Table 1. Comparative characteristic of surface parameters of parent silica gel and poly(4-vinylpyridine-co-styrene-comaleic anhydride)/silica gel composite.

\begin{tabular}{lccccc}
\hline & \multicolumn{3}{c}{ Surface area, $\mathrm{m}^{2} / \mathrm{g}$} & & \\
\cline { 2 - 4 } & $\mathrm{P} / \mathrm{P}_{0}$ & $\mathrm{BET}$ & Langmuir & Average pore volume, $\mathrm{cm}^{3} / \mathrm{g}$ & Average pore diameter, $\mathrm{nm}$ \\
\hline Silica gel & 446.97 & $463.53 \pm 0.89$ & $686.91 \pm 23.68$ & $0.686 \pm 0.003$ & $5.92 \pm 0.01$ \\
Composite & 70.33 & $73.94 \pm 0.14$ & $110.76 \pm 3.82$ & $0.138 \pm 0.003$ & $7.47 \pm 0.01$ \\
\hline
\end{tabular}

In [8], we describe the results of in situ immobilization of 4-vinylpyridine and styrene copolymer on silica gel surface. The synthesized composite material showed high sorption ability towards microquantitatives of $\mathrm{Pb}$ (II), $\mathrm{Cd}$ (II), $\mathrm{Zn}$ (II), $\mathrm{Cu}$ (II) and $\mathrm{Fe}$ (III) ions.

The presented paper deals with in situ immobilization on silica gel surface organic layer of poly(4-vinylpyridine-co-styrene-co-maleic anhydride) as well as its adsorption characteristics with respect to $\mathrm{Cu}(\mathrm{II}), \mathrm{Cd}(\mathrm{II}), \mathrm{Pb}(\mathrm{II}), \mathrm{Mn}(\mathrm{II}), \mathrm{Fe}(\mathrm{III})$, and $\mathrm{Ni}(\mathrm{II})$ ions.

\section{Experimental}

Silica gel (fraction of $0.1-0.2-\mathrm{mm}$ diameter particles, specific surface $428.61 \mathrm{~m}^{2} / \mathrm{g}$, Merck) was used as inorganic carrier of composite. Properties of the silica gel are given in Table 1.

Styrene (Merck) and 4-vinylpyridine (reagent grade, Ukraine) were distilled under vacuum and stored under argon at $3-5^{\circ} \mathrm{C}$. The reagent grade $2,2^{\prime}$-azobis(2- methylpropionitrile) (AIBN, Ukraine) served as an initiator of their radical polymerization. Maleic anhydride (Sigma-Aldrich Inc.) and other chemicals of p.a. quality (Sigma-Aldrich Inc.) were used as received.

Composite silica gel/poly(4-vinylpyridine-co-styrene-co-maleic anhydride) was obtained by radical copolymerization of 4 -vinylpyridine, styrene and maleic anhydride in the presence of silica gel.

Synthesis of composite was performed as follows: $0.36 \mathrm{~g}(3.46 \mathrm{mmol})$ of styrene, $0.65 \mathrm{~g}$ of maleic anhydride $(3.46 \mathrm{mmol})$ and $2.68 \mathrm{~g}(25.5 \mathrm{mmol})$ of 4 -vinylpyridine with $0.04 \mathrm{~g}$ of 2,2-azobis(2-methylpropionitrile) (AIBN) were dissolved in $10 \mathrm{ml}$ of $\mathrm{CCl}_{4}$ and added into the reactor with $5 \mathrm{~g}$ of silica gel while stirring. An inert atmosphere was created by argon blowing during $20 \mathrm{~min}$. After the interruption of argon blowing, the reaction mixture was heated to $75^{\circ} \mathrm{C}$. This temperature was maintained during $3 \mathrm{~h}$. Then the reaction mixture was cooled, and the obtained suspension was filtered off. After filtration the suspension was washed with $\mathrm{CCl}_{4}$, then washed with propanol-2 thrice to remove residual monomers and dried at room temperature during $24 \mathrm{~h}$.

The scheme of in situ immobilization of 4-vinylpyridine-styrene-maleic anhydride copolymer on silica gel surface is presented in Fig. 1.

FT-IR spectra of the parent silica gel as well as silica gel with immobilized copolymer were recorded using an IR spectrometer with Fourier transformation (Perkin Elmer, Germany). The samples were pressed with $\mathrm{KBr}$. The FT-IR spectra were recorded in a spectral range $500-4000 \mathrm{~cm}^{-1}$.

The amount of immobilized copolymer on the silica gel surface was evaluated by thermo-gravimetric analysis. The data were obtained with TG/DTA analyzer "Shimadzu DTG-60 H" (Shimadzu, Japan) in the range $15-1000{ }^{\circ} \mathrm{C}$ with heating rate $10^{\circ} \mathrm{C} \mathrm{min}^{-1}$. 

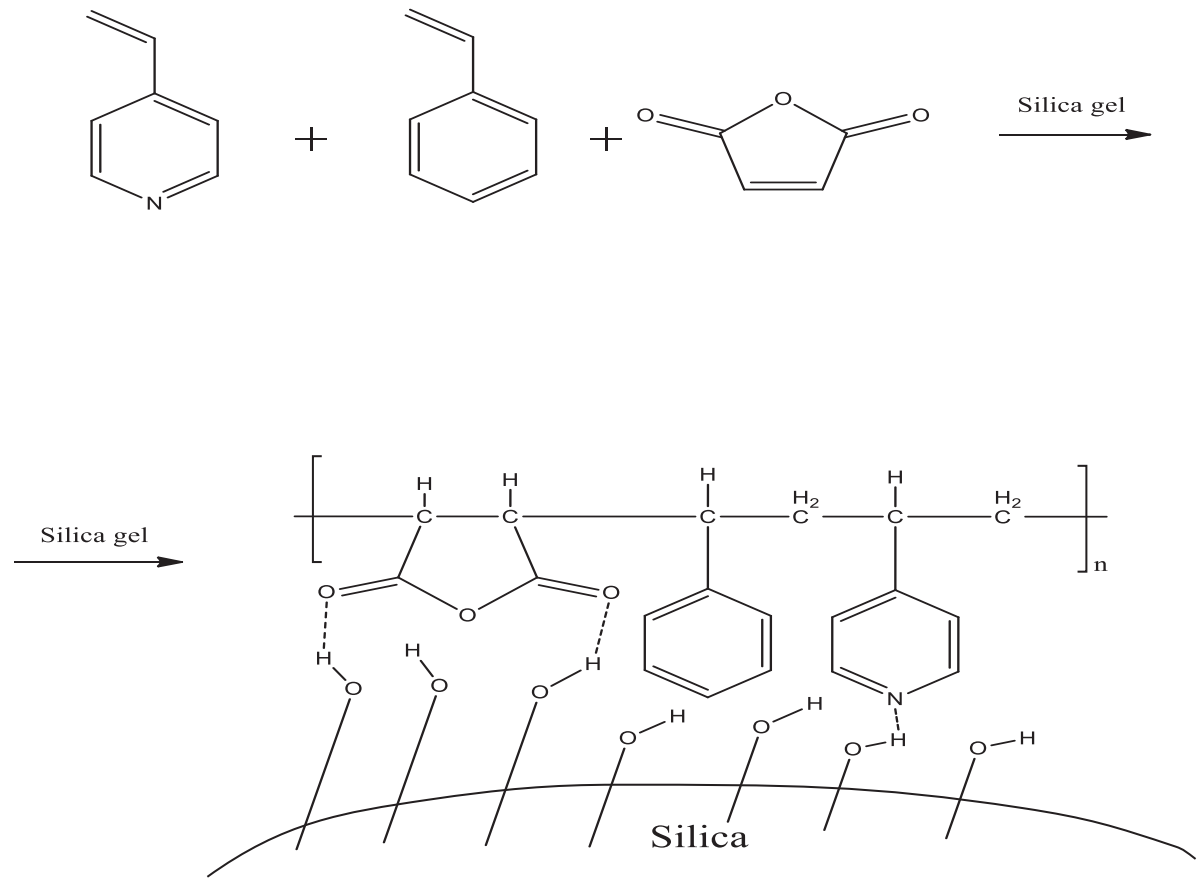

Figure 1. The scheme representation of in situ immobilization of copolymer poly(4-vinylpyridine-costyrene-co-maleic anhydride) on silica gel surface.

Thermal analysis was carried out on STA 449 Jupiter F1, Netzsch (Germany) under the following operational conditions: heating rate $10^{\circ} \mathrm{C} \mathrm{min}^{-1}$, dynamic atmosphere of synthetic air $\left(50 \mathrm{~mL} \mathrm{~min}^{-1}\right)$, temperature range $30-950{ }^{\circ} \mathrm{C}$, samples masses $25-29 \mathrm{mg}$, sensor thermocouple type $\mathrm{S}$ TG-DSC. As a reference, empty $\mathrm{Al}_{2} \mathrm{O}_{3}$ crucible was used. The gaseous products emitted during decomposition of material were analyzed by QMS 403C Aeölos (Germany) coupling on-line to STA instrument. The QMS data were gathered in the range from 10 to $160 \mathrm{amu}$.

The surface area of the composite as well as pore diameter and their distribution was calculated using data of low-temperature adsorption-desorption of nitrogen obtained with ASAP 2420 V1.01 (Micromeritics, USA) sorptometer. Samples were degassed at $60^{\circ} \mathrm{C}$ during 24 hours before measuraments.

The surface morphology of composite as well as parent silica gel was observed by scanning electron microscope SEM, LEO 1430VP (Carl Zeiss, Germany).

The adsorption properties of the obtained composite with respect to $\mathrm{Cu}(\mathrm{II}), \mathrm{Cd}(\mathrm{II})$, $\mathrm{Pb}$ (II) and $\mathrm{Fe}(\mathrm{III})$ ions were measured in a static mode. For that, $0.1 \mathrm{~g}$ of each sample of the composite were put into an interaction with $25-100 \mathrm{~mL}$ of nitrate working solutions of corresponding metals. The interaction took place for 10, 30, 60, 90 minutes and 24 hours with mechanical shaking. The equilibrium concentration of metal ions was determined by atomic absorption method.

Nitrate working solutions of $\mathrm{Cu}(\mathrm{II}), \mathrm{Cd}(\mathrm{II}), \mathrm{Pb}(\mathrm{II})$ and $\mathrm{Fe}(\mathrm{III})$ were prepared using sets "standard sample solutions set" of these salts against the background of $1 \mathrm{M} \mathrm{HNO}_{3}$ (manufactured by A.V. Bogatsky FHI Co, in Odesa) with 1 and $10 \mathrm{mg} / \mathrm{ml}$ concentrations. 
Solution with $\mathrm{pH} 4$ was prepared from the standard phthalate buffer ("standard sample solutions set" DSTU 8.135:2009, «RIAP», Kyiv, Ukraine). Solution with pH $1.2 \pm 0.02$ was prepared by addition of $0.1 \mathrm{M} \mathrm{HCl}$, solution with $\mathrm{pH} 2.8 \pm 0.02$ was prepared by addition of $0.1 \mathrm{M}$ of acetic acid. The exact $\mathrm{pH}$ values for all prepared solutions were controlled by $\mathrm{pH}$-meter "HANNA TESTER WP" (Hanna instrument, China).

The adsorption capacity $(A)$ was calculated using the formula:

$$
A=\left(c_{\mathrm{O}}-[\mathrm{M}]\right) \mathrm{V} / \mathrm{m}
$$

where $c_{o}$ - an initial molar concentration of metal, $[\mathrm{M}]$ - equilibrium molar concentration of metal, $V$ - is the volume of the working solution, $m$ - is mass of the adsorbent (g).

The adsorption rate $(\mathrm{R})$ was calculated according to the equation:

$$
R=\left(m_{a d s} / m_{\mathrm{o}}\right) \cdot 100 \%=\left(m_{\mathrm{o}}-[m]\right) / m_{\mathrm{o}} \cdot 100
$$

where $m_{o}$ - is mass of metal in the starting solution $(\mathrm{mkg}), m_{a d s}$ - is mass of the metal adsorbed, $[m]$ - is mass of the metal at equilibrium after the adsorption, which was found $[m]=\mathrm{C} \cdot V$, where $\mathrm{C}-$ is concentration of the metal at equilibrium $(\mathrm{mrg} / \mathrm{ml})$ and $V$ - is the volume of the solution at equilibrium $(\mathrm{ml})$.

The equilibrium concentrations of the metals were determined by atomic absorption spectroscopy using a flame atomic absorption spectrophotometer "Saturn"(Ukraine) in "air-propane-butane flame mixture.

The characteristics wavelengths for measurements were used: $324.7 \mathrm{~nm}$ for $\mathrm{Cu}$, $228.8 \mathrm{~nm}$ for $\mathrm{Cd}, 283.3 \mathrm{~nm}$ for $\mathrm{Pb}$ and $248.3 \mathrm{~nm}$ for Fe with $0.58 \mathrm{~cm}$ slit width. The calculations of the equilibrium concentrations in the solution were made by comparing the intensities of their lines in the spectrum with the intensity of the lines of standard solutions. For this purpose, standard solutions were prepared with concentration of metal $0.1-1.5 \mu \mathrm{g} / \mathrm{ml}$, experimental error for $\mathrm{Pb} 0.01 \mu \mathrm{g} / \mathrm{ml}$, for $\mathrm{Cu}$ and $\mathrm{Cd} 0.005 \mu \mathrm{g} / \mathrm{ml}$.

\section{Results and Discussion}

The immobilization of copolymer poly(4-vinylpyridine-co-styrene-co-maleic anhydride) on the silica gel surface could be recognized visually due dark yellow color of the obtained composite. The more detailed evidences were obtained by FT-IR spectroscopy. The corresponding spectra of the parent silica gel (1) and synthesized composite (2) are presented in Fig. 2.

Comparative analysis of FTIR spectra of the synthesized composite and original silica gel (Fig. 2) shows that absorption bands are present at $1605 \mathrm{~cm}^{-1}$ in the spectrum of the immobilized copolymer unlike the original carrier, which can be identified as $\nu(\mathrm{C}$ C) vibrations of the aromatic core in styrene and 4-vinylpyridine and $\nu(\mathrm{C}-\mathrm{N})$ vibrations in 4-vinylpyridine. Signals what could be attributed to the aromatic systems are also present in the spectrum at $3070 \mathrm{~cm}^{-1} \nu(\mathrm{CH})[9,10]$.

Absorption bands in the region $1380-1480 \mathrm{~cm}^{-1}$ could be attributed to the stretching vibration of $\delta\left(\mathrm{CH}_{2}\right)$ of the polymer chain. The main chain of copolymer also gives rise to $\nu(\mathrm{CH})$ vibrations at $2930 \mathrm{~cm}^{-1}$.

Absorption band at $2340 \mathrm{~cm}^{-1}$ was attributed to $\nu(\mathrm{Si}-\mathrm{H})$ vibration and is an evidence of hydrogen bonding of copolymer with the silica gel surface. 


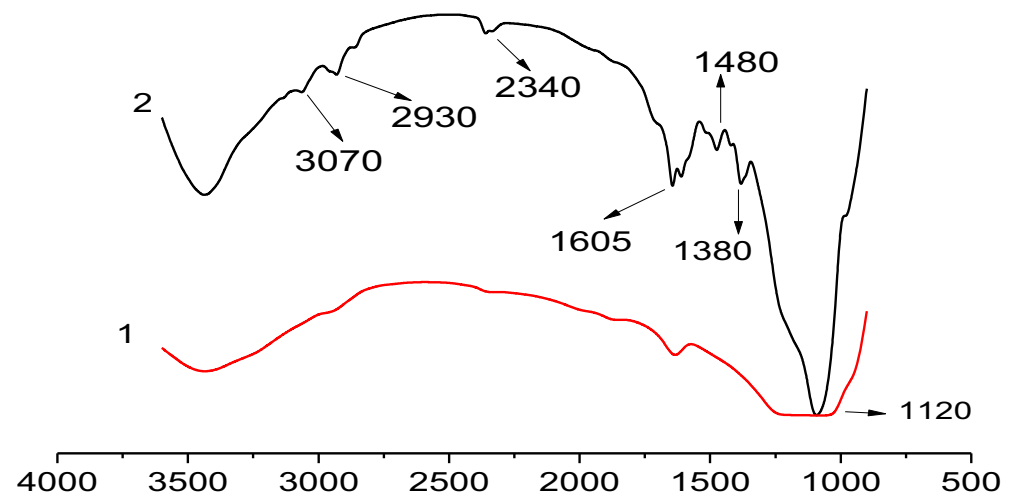

Figure 2. FTIR-spectra of the original silica gel (1) and composite poly(4-vinylpyridine-co-styrene-comaleic anhydride)/silica gel (2).

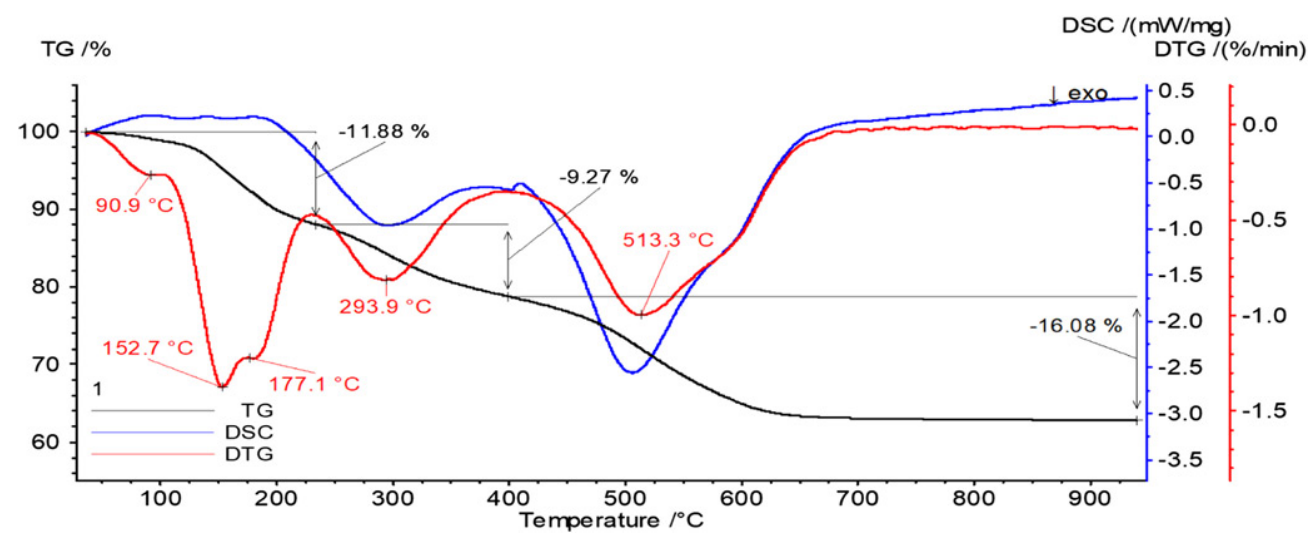

Figure 3. TG, DTG, DSC curves of composite poly(4-vinylpyridine-co-styrene-co-maleic anhydride)/silica gel.

In the composite spectrum there is an absorption band at $1120 \mathrm{~cm}^{-1}$ due to $\nu(\mathrm{C}-\mathrm{O}$ C) vibration of maleic anhydride fragment. Thus, FTIR spectroscopy data confirme an existance of poly(4-vinylpyridine-co-styrene-co-maleic anhydride) on the silica gel surface.

A comparative analysis of TG and DSC-MS data for the parent silica gel and composite obtained was employed in order to estimate the mass ratio of copolymer in the composite. The obtained thermograms are shown in Figures 3 and 4. From Figure 3 it can be seen that the most active thermodestruction of the composite occurs in the temperature range $90-650^{\circ} \mathrm{C}$. The weight loss is about $37.23 \mathrm{wt} . \%$. This loss is mainly due to the loss of residual water of the silica gel (about 5.39 wt.\%, see Fig.4) and thermal degradation of polymer. Consequently, the mass of the immobilized polymer could be estimated as $31.84 \pm 0.1 \mathrm{wt} . \%$.

In order to detail the process of thermal destruction of the composite, its thermogram and 3D mass spectrum (Fig. 5) as well as series of 2D mass spectra at 92.4, 154.2, 174.9 (Fig. 6), 292 and $511.2^{\circ} \mathrm{C}$ were examined. 


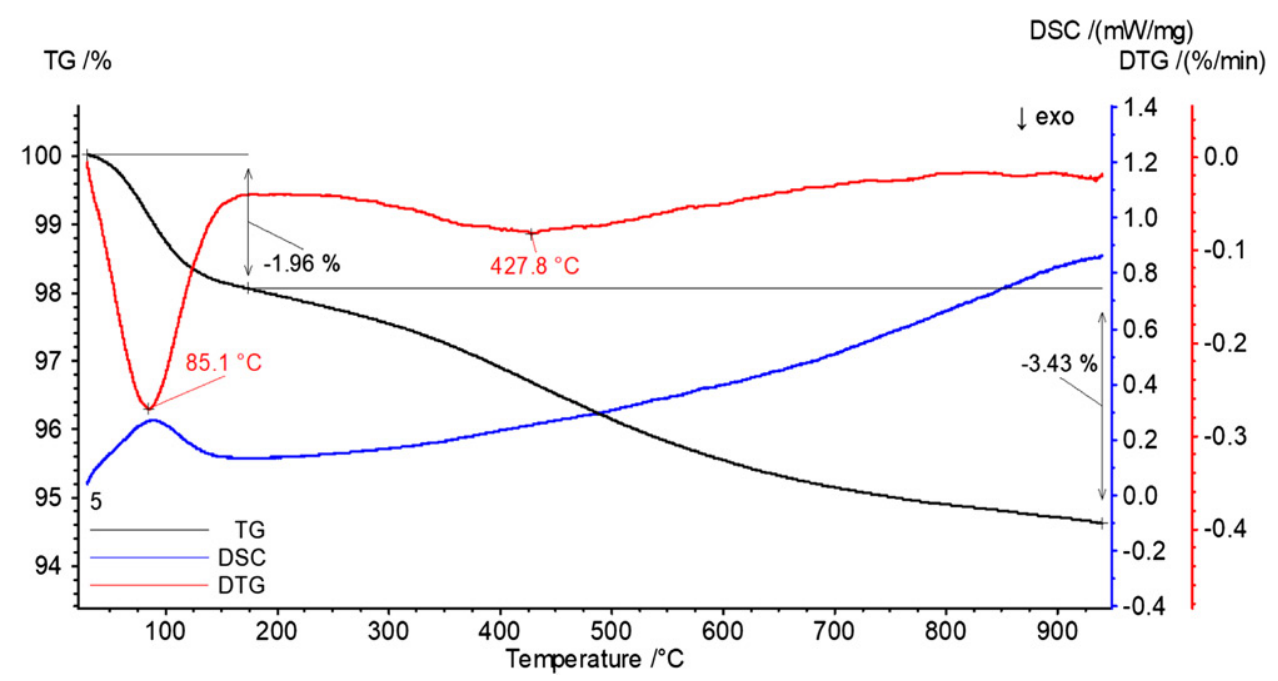

Figure 4. TG, DTG, DSC curves of parent silica gel.

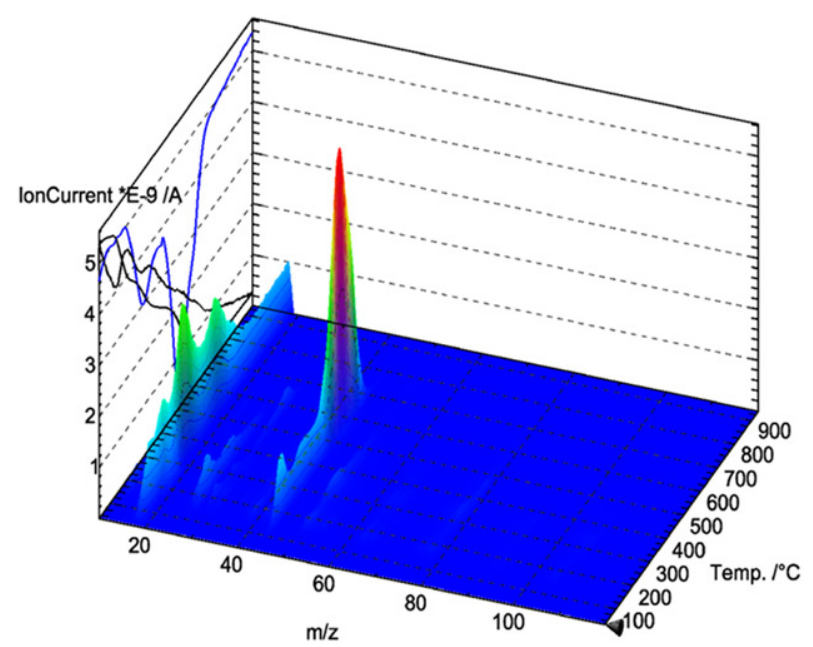

Figure 5. TG-MS-3D data for poly(4-vinylpyridine-co-styrene-co-maleic anhydride)/silica gel composite.

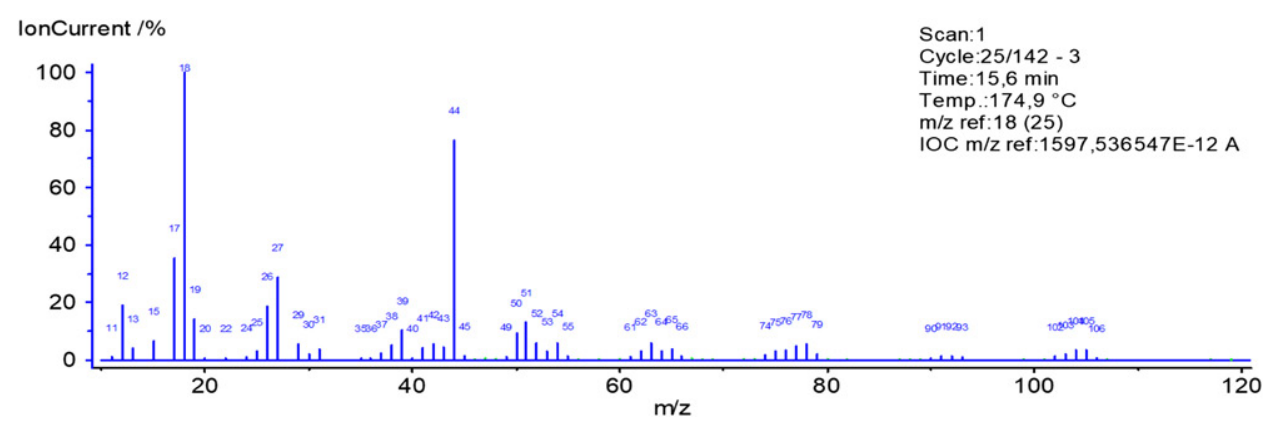

Figure 6. MS-2D of synthesized composite, $\mathrm{T}=174,9^{\circ} \mathrm{C}$. 
The first decomposition stage of the obtained composite was detected at $90-120^{\circ} \mathrm{C}$ with weight loss $\sim 1 \mathrm{wt} . \%$. It is obvious that this loss is due to the evaporation of residual water in the silica gel, which is confirmed by the presence of intencive peak at $18 \mathrm{Da}$ in the mass spectrum at $92.4^{\circ} \mathrm{C}$. The next significant mass loss occurring in the temperature range $154.2^{\circ} \mathrm{C}-174.9^{\circ} \mathrm{C}$ due to thermal degradation of the polymer. These considerations are confirmed with high intensity peaks in the mass spectra at $18 \mathrm{Da}\left(\mathrm{H}_{2} \mathrm{O}\right)$ and $44 \mathrm{Da}\left(\mathrm{CO}_{2}\right)$ in the same temperature region (Fig. 6).

Low intensity signal at $26 \mathrm{Da}$ can indicate the formation of $\mathrm{CN}$ radical, other peaks in the regions $49-55 \mathrm{Da}, 61-66 \mathrm{Da}$ and $74-79 \mathrm{Da}$ could be attributed to the fragments of decomposed polymer chain.

In the temperature range $200-500{ }^{\circ} \mathrm{C}$ decomposition of the immobilized copolymer gives predominantly $\mathrm{CO}_{2}, \mathrm{~N}_{2} \mathrm{O}$ (signal at $44 \mathrm{Da}$ ) and $\mathrm{H}_{2} \mathrm{O}(18 \mathrm{Da})$.

The final polymer destruction was observed at the temperature above $500{ }^{\circ} \mathrm{C}$. MS analysis confirmed the formation of organic carbon $(12 \mathrm{Da}), \mathrm{H}_{2} \mathrm{O}(18 \mathrm{Da})$ and $\mathrm{N}_{2} \mathrm{O}$ $(44 \mathrm{Da})$ at this stage.

To study the surface parameters of silica gel after immobilization of poly(4-vinylpyridine-co-styrene-co-maleic anhydride) on the surface, a low-temperature nitrogen adsorption-desorption method was employed. Nitrogen adsorption-desorption isotherms obtained for silica gel and for the composite are similar and belong to type IV isotherms according to IUPAC classification [11]. The received data indicate that immobilized copolymer has virtually no effect on the structure of the silica gel surface. Calculated by computer processing of nitrogen adsorption-desorption isotherms data are shown in Table 1 for the composite and the parent silica gel.

It is evident that after immobilization of a large amount of copolymes (31.84 wt.\%), the porosity of the silica gel surface is significantly reduced; the surface area decreases from 447 to $70.33 \mathrm{~m}^{2} / \mathrm{g}$, the average pore volume decreases from 0.686 to $0.138 \mathrm{~cm}^{3} / \mathrm{g}$, and the average pore diameter slightly increases from 5.92 to 7.47 .

To clarify the geometry and location of poly(4-vinylpyridine-co-styrene-co-maleic anhydride) on the silica gel surface SEM-microphotographs of synthesized composite at $500 \times(\mathrm{A}), 10000 \times(\mathrm{B})$ magnification (Fig. 7) were obtained. As one can see, the immobilized polymer located on the surface of silica gel irregularly.

As one can see, the polymer on the inorganic carrier surface is located in the form of macrochain loops, coils and aggregates of coils.

In accordance with literature data, composite should exhibit an adsorption behaviour towards transition metals due to pyridine as well as maleic anhydride complexing properties of the immobilized copolymer units.

To confirm these considerations, sorption properties towards ions mentioned above with high affinity to such Nitrogen-containing ligands as $\mathrm{Cu}$ (II) and Fe (III) were investigated [12]. Also, good complexing of such metals as $\mathrm{Cd}$ (II) and $\mathrm{Pb}$ (II) with Oxygen should be taken into account [12].

Investigations of composite sorption properties included:

- determination of the optimal pH of the sorption medium;

- establishing phases contact time required to achieve the sorption equilibrium in the static mode; 


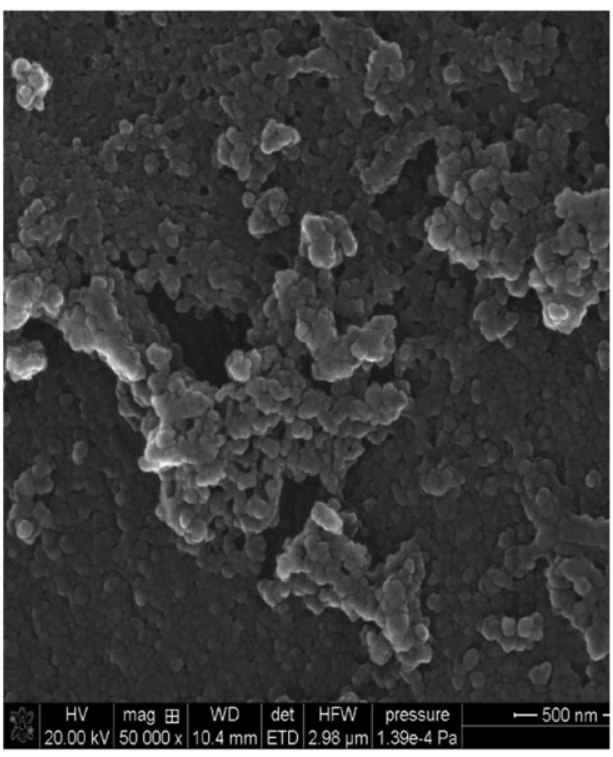

(a)

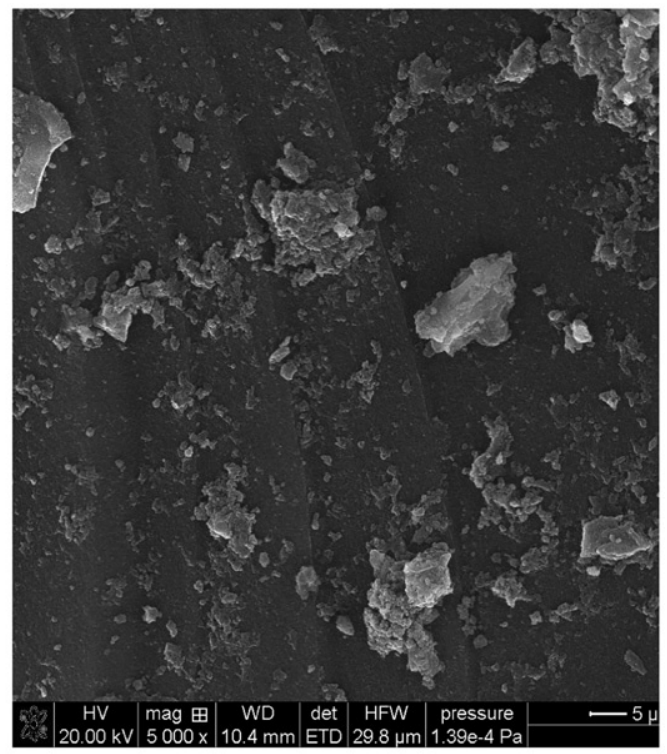

(b)

Figure 7. SEM-microphotographs of synthesized composite at $\times 500000$ (a) and $\times 5000$ (b) magnification.

- plotting of sorption isotherms for each of the investigated metal ions on the composite surface;

- sorption capacity estimation for metal ions and comparison with the data obtained with the parent silica gel.

It should be noted that in a weakly-alkaline medium $\left(\mathrm{NaHCO}_{3}\right.$ solution, $\left.\mathrm{pH} 8.1\right)$, partial flushing of the immobilized copolymer from silica gel surface was observed (the solution became yellow). Therefore, sorption properties of the synthesized composite were investigated in an acidic and neutral medium.

As we believe, aqua, chloride, acetate or phthalate coordination spheres of the investigated metals were formed in the initial solutions. Sorption occurs due to the complexes interaction with the macromolecules of immobilized copolymer leading to the formation on solid surface multi-ligand complexes.

The results of sorption activity studies of silica gel with immobilized poly(4-vinylpyridine-co-styrene-co-maleic anhydride) towards $\mathrm{Cu}$ (II), $\mathrm{Cd}$ (II), $\mathrm{Pb}$ (II) and $\mathrm{Fe}$ (III) ions at different $\mathrm{pH}$ values and various chemical composition the medium are shown in Table 2 .

The highest sorption activity was detected towards microquantities $\mathrm{Cu}$ (II) ions in a neutral medium and towards $\mathrm{Pb}$ (II) and Fe (III) ions in a slightly acidic medium (on the background of phthalate buffer). A sorption activity towards Cd (II) ions was not detected. It can be assumed that $\mathrm{Cd}$ complexes with a copolymer are less stable than $\mathrm{Pb}$ complexes. Assumption that the sorption of metal ions occurs due to their complexation with the polymer, may be the reason of low sorption ability of the composite toward Cd(II) ions. 
Table 2. Dependence of $\mathrm{Cu}(\mathrm{II}), \mathrm{Cd}(\mathrm{II}), \mathrm{Pb}(\mathrm{II})$ and $\mathrm{Fe}(\mathrm{III})$ cations adsorption degree on the composite surface from $\mathrm{pH}$ and composition of initial solutions (Experimental conditions: $0.1 \mathrm{~g}$ sorbent mass, volume of solutions $-25 \mathrm{~mL}, \mathrm{~m}^{0}$ ме $-100 \mu \mathrm{g}$, interection time $24 \mathrm{~h})$.

\begin{tabular}{lrrrr} 
& \multicolumn{4}{c}{ Degree of sorption, $\% \pm 2 \%$} \\
\cline { 2 - 5 } $\mathrm{pH}$ & $\mathrm{Cu}^{2+}$ & $\mathrm{Cd}^{2+}$ & $\mathrm{Pb}^{2+}$ & $\mathrm{Fe}^{3+}$ \\
\hline $1.2 \pm 0.02$ & 1.12 & 13.12 & 4.40 & 6.74 \\
$2.8 \pm 0.02$ & 40.85 & 17.20 & 26.05 & 69.66 \\
$4.0 \pm 0.02$ & 69.46 & 14.58 & 98.97 & 96.35 \\
5.5 (Distilled water) & 82.89 & 15.45 & 66.15 & 79.49 \\
\hline
\end{tabular}

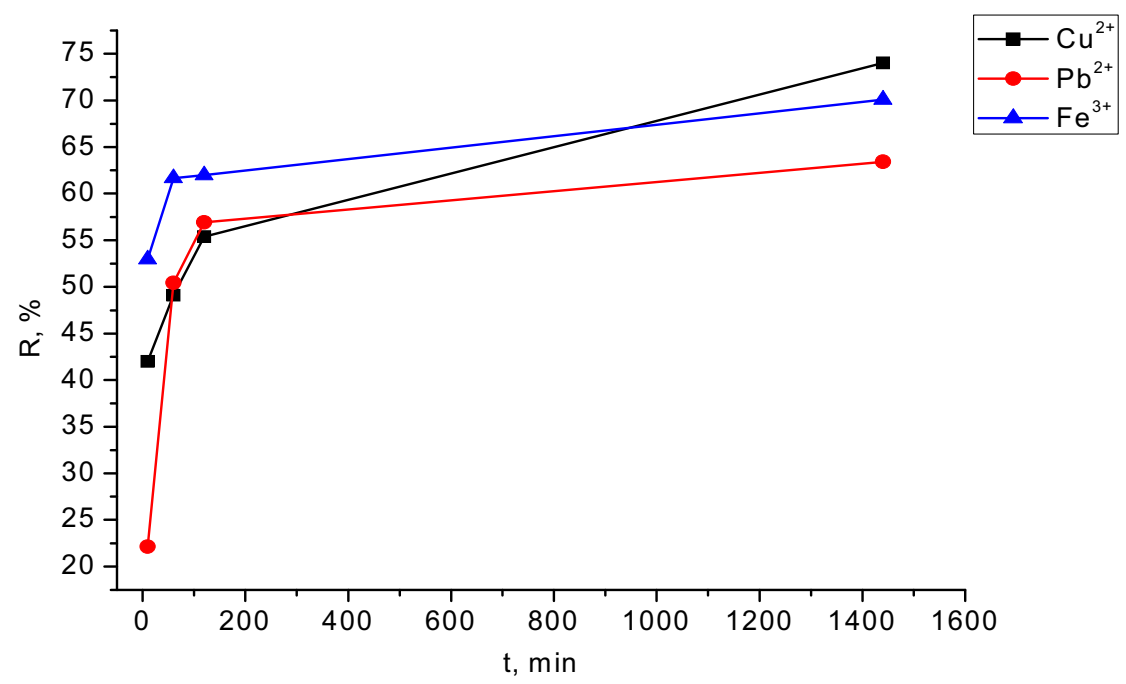

Figure 8. The dependence of $\mathrm{Cu}$ (II), $\mathrm{Pb}$ (II) and Fe (III) ions sorption degree (R, \%) from the interaction time with the composite in the static mode.

Taking into account all of the foregoing, further investigations of sorption properties of the composite were carried out with the initial solutions of $\mathrm{Cu}$ (II) nitrate without adding buffers, and with $\mathrm{Pb}$ (II) and $\mathrm{Fe}$ (III) nitrates against the background of phthalate buffer.

The dependence of $\mathrm{Cu}$ (II), $\mathrm{Pb}$ (II) and Fe (III) ions sorption degree (R, \%) on the silica gel surface with in situ immobilized poly(4-vinylpyridine-co-styrene-co-maleic anhydride) from the interaction time in the static mode is shown in Figure 8.

The data obtained confirm that the maximum sorption takes place during the first day of the contact and sorption equilibrium is established after 24 hours. Such a small rate of sorption, according to the literature, is typical for the polymers or organo-mineral composites with more than $20 \mathrm{wt}$.\% of the immobilized polymer.

In order to establish the values of silica gel with immobilized copolymer adsorption capacity towards $\mathrm{Cu}(\mathrm{II}), \mathrm{Cd}(\mathrm{II}), \mathrm{Pb}$ (II) and $\mathrm{Fe}(\mathrm{III})$ ions, adsorption isotherms were measured. The isotherms were obtained for aqueous solutions of nitrates of these metals (without adding any buffer solutions) in static mode and compared with the initial silica gel. The isotherms obtained for $\mathrm{Cu}(\mathrm{II})$ Ta $\mathrm{Pb}(\mathrm{II})$ are shown in Figure 9. All of the obtained adsorption isotherms are 2L-type in accordance with IUPAC [11] classification. The isotherms obtained were employed for adsorption capacity calculations. 


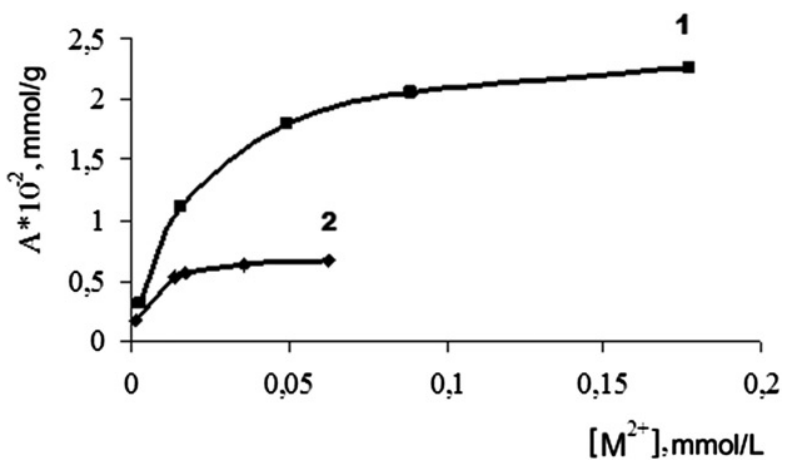

Figure 9. Sorption isotherms for $\mathrm{Cu}(\mathrm{II})$ (curve 1) and $\mathrm{Pb}(\mathrm{II})$ (curve 2) ions on the surface of poly(4vinylpyridine-co-styrene-co-maleic anhydride)/silica gel composite.

Table 3. Comparison of parent silica gel, poly(4-vinylpyridine-co-styrene)/silica gel composite [8] and poly(4-vinylpyridine-co-styrene-co-maleic anhydride)/silica gel sorption capacities towards $\mathrm{Cu}(\mathrm{II}), \mathrm{Cd}(\mathrm{II}), \mathrm{Pb}$ (II) and $\mathrm{Fe}(\mathrm{III})$ ions.

\begin{tabular}{lccc}
\hline & \multicolumn{3}{c}{ Sorption capacity, $\mathrm{mmol} / \mathrm{g} \pm 0.001$} \\
\cline { 2 - 4 } lon & Parent silica gel & $\begin{array}{c}\text { Silica gel with } \\
\text { immobilized poly } \\
\text { (4-vinylpyridine-co-styrene) }\end{array}$ & $\begin{array}{c}\text { Silica gel with immobilized } \\
\text { poly(4-vinylpyridine-co- } \\
\text { styrene-co-maleic anhydride) }\end{array}$ \\
\hline $\mathrm{Fe}(\mathrm{III})$ & $0.008[8]$ & $0.027[8]$ & 0.015 \\
$\mathrm{~Pb}(\mathrm{II})$ & $0.002[8]$ & $0.075[8]$ & 0.0067 \\
$\mathrm{Cu}(\mathrm{II})$ & $0.005[8]$ & $0.029[8]$ & 0.025 \\
\hline
\end{tabular}

Sorption capacity values for $\mathrm{Cu}$ (II), $\mathrm{Pb}$ (II) and $\mathrm{Fe}$ (III) ions calculated using sorption isotherms for the synthesized composite poly(4-vinylpyridine-co-styrene-co-maleic anhydride)/silica gel as well as literature data for the original silica gel and composite poly(4-vinylpyridine-co-styrene)/silica gel [8] are given in Table 3.

The data presented in Table 3 confirm that sorption capacity of silica gel after modification with poly(4-vinylpyridine-co-styrene-co-maleic anhydride) is increased in 1.88 times for $\mathrm{Fe}$ (III) ions, in 5.00 times for $\mathrm{Cu}$ (II) ions and in 3.35 times for $\mathrm{Pb}$ (II) ions.

However, the sorption capacity of poly(4-vinylpyridine-co-styrene-co-maleic anhydride)/silica gel composite towards $\mathrm{Pb}$ (II), $\mathrm{Cu}$ (II) and Fe (III) ions is lower than sorption capacity of poly(4-vinylpyridine-co-styrene)/silica gel composite.

This result can be explained by two reasons. Firstly, the high mass of the immobilized copolymer (31.84 wt.\%) reduces the silica gel matrix porosity. Secondly, non-uniform location of the copolymer on the silica gel surface (see Fig. 7, a.) leads to the sterical hindrance for incorporation of complexing copolymer centers into the coordination spheres of metal ions.

\section{Conclusions}

Precipitation polymerization was employed for the syntheses of a new mineral-organic composite by in situ immobilization of poly(4-vinylpyridine-co-styrene-co-maleic anhydride) on the silica gel surface. The immobilization of copolymer on a silica gel surface was confirmed by FTIR spectroscopy. 
A thermal decomposition of the immobilized copolymer was investigated by thermogravimetry and mass spectrometry and described in detail. According to TG-analysis, the composite contained $31.84 \pm 0.1 \mathrm{wt}$.\% of immobilized copolymer.

The highest sorption capacity of a new composite towards micro-quantities of $\mathrm{Cu}$ (II) ions was established in neutral medium as well as towards $\mathrm{Pb}$ (II) and Fe (III) ions in a slightly acidic medium with the background of phthalate buffer and no sorption activity towards Cd (II) ions.

Sorption process for $\mathrm{Cu}$ (II), $\mathrm{Pb}$ (II) and $\mathrm{Fe}$ (III) ions occurs gradually and equilibrium is established after 24 hours.

It was found that sorption capacity of silica gel increased in 1.88, 5.00 and 3.35 times for $\mathrm{Fe}$ (III), $\mathrm{Cu}$ (II) and $\mathrm{Pb}$ (II) ions respectively after immobilization of poly(4-vinylpyridine-co-styrene-co-maleic anhydride) on silica gel surface. However, the sorption capacity of a new composite towards $\mathrm{Pb}$ (II), $\mathrm{Cu}$ (II) and $\mathrm{Fe}$ (III) ions is lower than sorption capacity of early obtained poly(4-vinylpyridine-co-styrene)/silica gel composite [8].

\section{References}

[1] Skopenko, V.V., Savranskij, L.I. (2004). Coordination Chemistry. Lybid: Kyiv, Ukraine (in Ukrainian).

[2] Skopenko, V.V., Grigoreva, V.V. (1996). The main classes of inorganic compounds. Lybid: Kyiv, Ukraine (in Ukrainian).

[3] Li Xiaoli, Yu Guangqian, Li Yuliang (1994). Chinese journal of polymer science, 12, 185.

[4] Youning Chen,Wei Zhao, Juncai Zhang (2017). RSC Adv., 7, 4226.

[5] Dadashev, D.A., Tertykh, V.A., Yanovska, E.S., Yanova, K.V. (2012). Chemistry, physics and technology of surface, 3, 419.

[6] Yanovska, E. et al. (2017). In: Chemical engineering of polymers. (Production of Functional and Flexible Materials) Mukbaniani, O., Abodie, M., Tatrishvili, T. (Eds.), Chapter 4, Apple Academic Press, Inc.: Waretown, USA, 60.

[7] Yanovska, E., Vretik, L., Sternik, D. et al. (2016). French-Ukrainian Journal of Chemistry, $4,47$.

[8] Yanovska, E.S., Vretik, L.O., Nikolaeva, O.A. et al. (2017). Nanoscale Research Letters,12, 217.

[9] Gunzler, H., Gremlich, H.-U. (2002). IR Spectroscopy. An introduction. Wiley-VCH Verlag Gmbh, Weinheim.

[10] Tarasevich, B.N. (2012). IR spectra of the main classes of organic compounds. Reference materials. M.V. Lomonosov MSU: Moscow (in Russian).

[11] Parfitt, G.D., Rochester, C.H. (1986). Adsorption from solution at the solid/liquid interface. Mir: Moscow (in Russian). 